\title{
Editorial
}

\section{Customer first is the only way to resolve the marketing mix}

Journal of Direct, Data and Digital Marketing Practice (2016) 17, 155. doi:10.1057/dddmp.2016.2

The IDM Journal covers a lot of territory — the clue is in the name (direct, digital and data). That reflects the astonishing diversity of channels now available to marketers and the complex techniques that are covered under the umbrella term of marketing. To deal with this abundance, we sometimes narrow our focus to a single route to market, hence special issues on digital, mobile or data.

In this issue, unusually, we cover the full spectrum, from the fifty-year-old discipline of TV planning through to the still in test-mode Facebook Reactions. As ever, it is the expertise of the authors of these papers that helps to illuminate the issues and provides our readers with the practical insights, which the IDM Journal is focussed on delivering. Continually developing skills and staying up-to-date are ongoing challenges for marketers.

Sometimes, this is about getting across the emerging channels and their place in the marketing mix. As Jackson and Ahuja discuss in their whitepaper, 'Dawn of the digital age and the evolution of the marketing mix', change is the only constant in marketing. Only by putting the customer first can practitioners hope to find the right path for their brand through the swirl of opportunities they face.

At other times, it is important for the IDM Journal to keep looking at long-established media that newer marketers might never have used or that practitioners may have allowed to slip out of the mix. As Novak discusses in his whitepaper, 'Industry analysis of TV commercials: Do companies reflect audience profiles?', there is a constant risk that the opportunities which data provides to improve targeting are simply not being embraced.

Elsewhere, direct mail gets a (now rare) look in with the case study on how Gecko has overhauled Eurocamp's customer information mailing to make it highly personalized and relevant. The impact this has on customer satisfaction and bookings is clear — just check out the results achieved.

Email has been top of the marketing mix pick-list for so long that some digital marketers are now moving away from this channel, assuming it to be too crowded and devalued for consumers. Yet, as the DMA Email Benchmarking study shows, the call to action of relevant, timely and personal email is still as strong as ever - perhaps even more so among mobile consumers.

Marketers do not often think about the downside of their actions - how customers might game or cheat the processes they put in place. But as Stone points out in his review of the book, 'The dark side of CRM', every positive action can have an equal and opposite negative reaction. Marketers need to put customers first — and this includes being on their guard against the less scrupulous.

David Reed FIDM 